\title{
La nueva arquitectura y la ciudad
}

Gustavo Munizaga Vigil

\section{Filiación}

Arquitecto de la P. Universidad Católica de Chile, Master en Diseño Urbano en la Universidad de Harvard. Profesor e investigador en diversas universidades chilenas, y extranjeras, especialmente en EE.UU., Argentina, España, Brasil, Japón y Gran Bretaña.

\section{Resumen}

Intentando soslayar la convencional confrontación dialéctica entre el Modernismo y el Post-Modernismo por parecer insuficiente y hoy sólo académica, este artículo refiere cuatro modelos que más que históricos son paradigmáticos, de modo de develar la coyuntura del presente de la arquitectura ante la paradoja del pasado redescubierto que vuelve a ser una nueva propuesta.

\section{Palabras claves}

Modernismo, posmodernismo, paradigmas en arquitectura.

\section{Abstract}

The four paradigmatic models presented in this study, are pursued as an alternative to the traditional dialectic confrontation between Modernism and Post-modernism. These models pretend to expose the present state of architecture to the paradox of an architectural revival.

\section{Key words}

Modernism, postmodernism, paradigms in architecture.

\section{Sumario}

Introducción

Prospectiva: Prospectiva: ¿Una cuarta generación o el retro vanguardismo?

Los Paradigmas de la Forma Colectiva

Conclusión: Historia y Naturaleza, Ciencia y Participación

Referencias 


\section{Introducción}

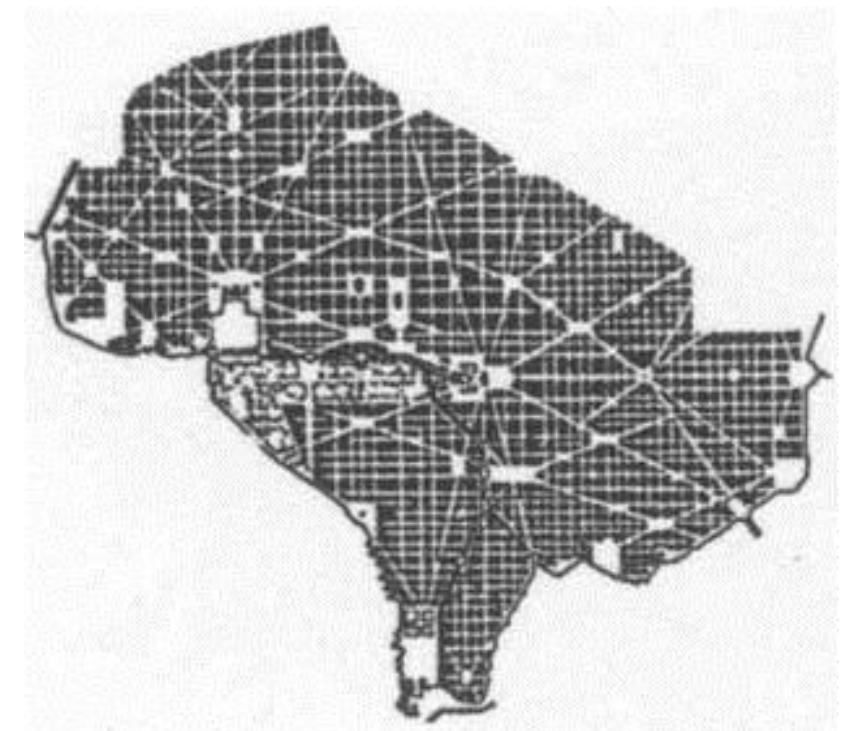

Fig.1. Plan de Washington. D.C., Pierre L'Enfant, 1971.

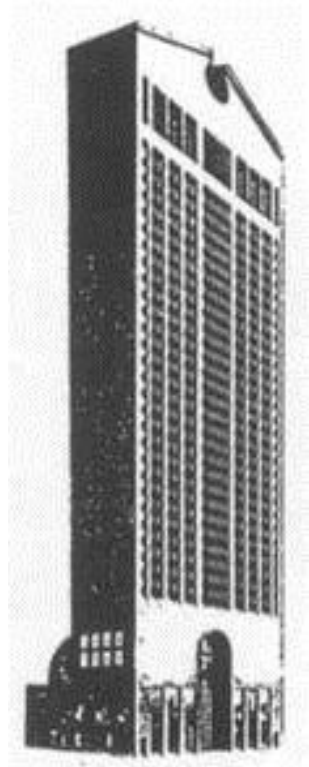

Fig.2. A.T. \& T., Nueva York, Philip Johnson, 1978-82.

Es difícil separar los temas de la arquitectura y ciudad, pues son sustantivos tanto como objetivos, una de la otra. El desarrollo del Diseño Urbano que las relaciona, 
podría verse desde los años 60, como la evolución secuencial y lógica de nuevas ideas y movimientos en torno a los diferentes aspectos de la arquitectura. No es así. Ya en el origen de la vertiente funcionalista moderna, hay un quiebre de tres "conflictos dialécticos"(1), una serie de contraposiciones que, desde la organización de la sociedad se extendieron al arte y la técnica, y de allí a la urbanística. Se cuestionó el rol tradicional del arquitecto, lo que originó y motivó especialmente a la primera y segunda generación del Constructivismo y Bauhaus y del Movimiento Moderno, CIAM. Por ello, hacia 1960, ni la estética de la máquina, los "prismas simples" en el espacio verde, ni las "cuatro funciones de la vida colectiva" base de la reforma del CIAM y de la nueva ciencia del Urbanismo, habían llevado la arquitectura de las ciudades a un estado de avance satisfactorio en el mundo occidental.

Otra vertiente del urbanismo, a la vez empírica y teórica, se gestó a partir del "problema de la ciudad" vista como un ente social, geográfico y económico. Ella se remonta a la génesis de las ciencias sociales y urbanas a fines del siglo XIX, especialmente en los EE.UU. e Inglaterra. Con un enfoque más amplio y anterior a la tradición CIAM, sólo en parte vino a complementarse con ésta después de 1950, principalmente en los países anglosajones. Se originó y definió desde las disciplinas nuevas: el "landscape architecture", el "town-planning" o el "city planning", hasta llegar al "regional planning".

El campo urbano incluiría disciplinas y teorías ya surgidas a fines del siglo XIX o inicios del XX: la Geografía, la Sociología Urbana y la localización Económica. Superando las connotaciones anteriores en EE.UU., se lo denominó "urbanología" en 1968 (2). Se intentaba una verdadera "ciencia de las ciudades", más allá de su mera fabricación arquitectónica. Tales especialidades y ciencias se llamaron más tarde Arquitectura, Arquitectura Paisajista, Planificación Regional, Planificación Urbana o Diseño Urbano. Como ciencias, Geografía, Sociología, Economía, Administración y finalmente, Ciencia Política. Desde 1960 y hasta hoy, estas disciplinas se han constituido en diversos programas, con conexiones interdisciplinarias bajo el tema común del "environmental design", el diseño ambiental, especialmente en los EE.UU., bajo la acción de grupos profesionales transdisciplinarios, y sobre todo, universitarios.

La tradición europea de la Escuela CIAM también mantuvo un carácter seudo "integralista". El Plan Mars de Londres, o el Grupo ASCORAL francés, definieron al arquitecto urbanista como el "jefe de equipo", el arquitecto hombre- síntesis, imagen idealizada que se mantuvo como la orientación profesional y universitaria hasta hace pocos años, principalmente en Francia y América Latina.

El período del 60 al 70 desarrollado a partir del último CIAM de Oterloo (1959), fue de transición entre las disciplinas del diseño y la planificación, coincidiendo con el primer curso de graduados en Diseño Urbano organizado por José Luis Sert en la Universidad de Harvard (1960). Desde 1961 se publicaron o constituyeron interesantísimos proyectos: la nueva ciudad de Hook Toulouse- Le Mirail: la Ciudad Universitaria de Berlín; el Plan de Washington 2000; Cumbernauld; Kosoji; Santo Tomé de Guayana; Halen; Milton Keynes, reflejando diferentes metodologías y configuraciones de diseño, 
e independizando cada vez más el campo del Diseño Urbano, de la Planificación y del Urbanismo del CIAM.

En 1963, en el Simposio de Delos de la Sociedad Mundial Ekística (Instituto Tecnológico de Atenas), se formuló la "Declaración de Delos", especie de Carta Magna de los Asentamientos Humanos. Personalidades, representando diversas disciplinas y países (3) hicieron un llamado que repercutió en los centros académicos y políticos de todo el mundo. En la administración pública se crearon en los EE.UU. y en Chile (1966) los primeros Ministerios de Vivienda y Desarrollo Urbano (o de Urbanismo) de las Américas. La gestión del proceso urbano cobraba reciente importancia, las estrategias y proyectos tendían a ser más integrales y el Estado y los organismos públicos se volvían más activos en políticas de uso de suelo, transporte, remodelación urbana o creación de nuevas ciudades y conjuntos habitacionales, especialmente en Europa.

En el campo de la teoría, surgieron textos que complementaron las obras básicas de Maki, Bacon y Spreiregen (4), y en los que desde distintos enfoques, se revisaron objetivos y métodos existentes: Urbanismo: Utopías y Realidad, de Françoise Choay (1965), revisó la historia y cuestiones sobre ideología y práctica en el Urbanismo. Notas sobre la síntesis de la forma, de Christopher Alexander (1968), impactó los medios académicos, especialmente de habla inglesa, al cuestionar los métodos y objetivos del diseño.

Diez años intensos de revisión y avance en Diseño Urbano, culminaron hacia 1973 con la Trienal de Milán, la fundación de la Revista "Oppositions" y del Instituto de Estudios Urbanos de Nueva York. El Diseño Urbano era la respuesta a una necesaria "arquitectura total" de la ciudad. Se avanzaba del voluntarismo técnico o del idealismo estético de los urbanistas arquitectos, a un mundo de urbanización explosiva. La ciudad dejaba de ser un artefacto, y el paisaje y los recursos naturales no podían estar ya al arbitrio de hechos irremediables. Existían elementos manejables y experiencias transmisibles, aunque el planeta estaba plagado de centros urbanos devastados e inhumanos, y con una arquitectura de calidad aún escasa.

Hacia 1970, nadie se sentía demasiado seguro de la calidad del ambiente de las "ciudades satélites" de Europa, de los "Siedlungen" alemanes, ni de los "town centers" británicos. Tampoco de la geométrica regularidad de Brasilia (Costa) o Chandigarth (Le Corbusier), de la forma y crecimiento de Daka (Kahn), de Islamabad (Doxiadis), de la Universidad de Bagdad (Gropius), ni de las nuevas ciudades de los califatos árabes. El Diseño Urbano y la arquitectura de la ciudad seguían entrelazados y, sin embargo, separados de los complejos problemas de gestión y habilitamiento del medio ambiente natural. 


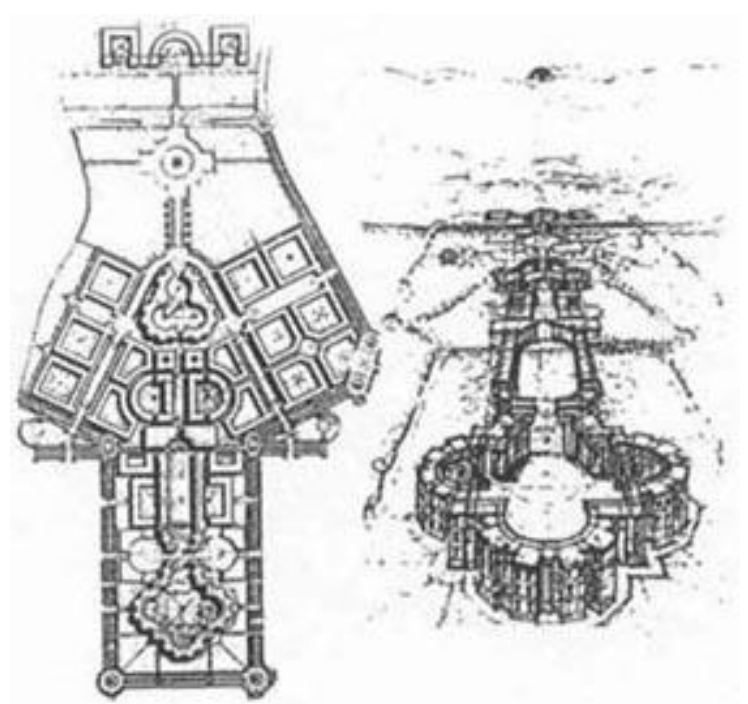

Fig. 3. "Antígona", Ricardo Bofill.

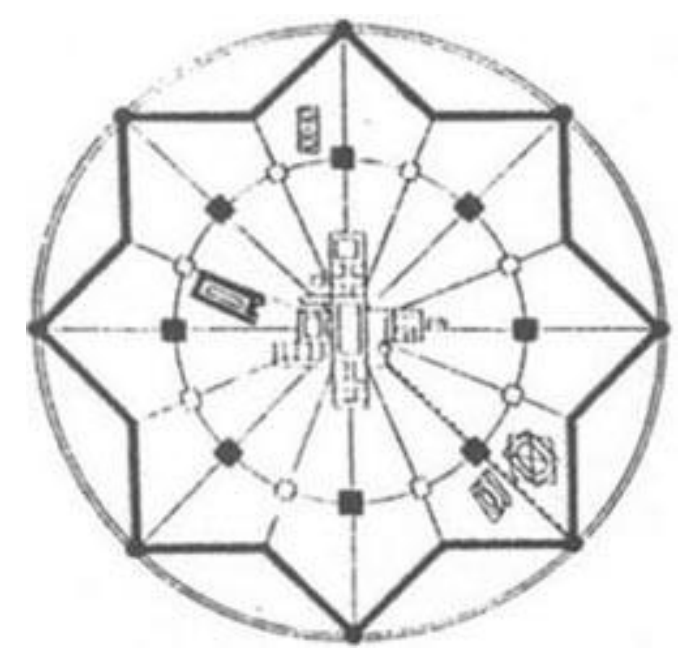

Fig. 4. Plan de ciudad ideal "Sforzinda", Filarete, 1464.

\section{Prospectiva: ¿Una cuarta generación o el retro vanguardismo?}

Charles Jencks observa seis tradiciones relevantes en la evolución de la arquitectura desde 1920, intentando predecir cómo se combinarán, o separarán en los 60 años 
siguientes. Ellas serían constantes y tendrían un efecto "oscilatorio", de vuelta a lo anterior (5):

La "tradición intuitiva" del Art Deco, culmina en los años 60 con la arquitectura "pop". Se asocia al naturalismo, al expresionismo, a lo orgánico y fantástico; al metabolismo y lo biofórmico (Aalto, Taut, van Velde, Scharoun, Kurokawa)

La "tradición lógica", origen del funcionalismo en los años 30, y las "megaformas" en los 80. Se relaciona a la ingeniería, lo funcional, estructural, geométrico y matemático; lo paramétrico o modular, la megaforma, el precisionismo industrial y la arquitectura ultra liviana (Freyssinet, Le Ricolais, Torroja, Arup, Nervi, F. Otto, Fuller, Alexander).

La "tradición inconsciente", da origen a la arquitectura espontánea, vernacular. Se expresa en corrientes populistas, eclécticas, hídridas, tradicionales, de autoconstrucción, móvil, ad- hocista, etc. (Eames, Fuller, Venturi, Hundertwasser, Pawley, tercermundistas, John Turner)(6).

La "tradición autoconsciente", que origina al "Beaux Arts" y la arquitectura fascista o formalista. Se destaca por la tradición académica del Beaux Arts francés, lo clásico, el historicismo, la arquitectura burocrática, reaccionaria y empresarial, el Post- Modern, por mencionar algunas (Perret, Terragni, Speer, Ponti, Troost, Utzon, Yamasaki, los Krier, Rossi, Graves).

La "tradición idealista", que origina el "estilo internacional" CIAM. Se expresa en las corrientes racionalistas, el purismo, la arquitectura heroica y metafísica, la cibernética y la significación (van Doesburgh, Aalto, Mies, Gropius, Neutra, Niemayer, Le Corbusier, Doxiadis, TAC, Roche).

La "tradición activista", comienza con el constructivismo y futurismo. Sigue con el revolucionarismo y el comunalismo, la arquitectura metafórica y desechable, el anarquismo, la arquitectura dinámica y el ideologismo (Lissistki, Tatlin, Vesnin, Meyer, Jacobs, Metabolismo). La vivienda de desechos de Pawley, R. Segre, Dos Santos, y Turner, en nuestra experiencia americana.

Estas clasificaciones parecen acertadas. El efecto de péndulo se produce, entre 1920 y los años 60, la arquitectura que surgió, y los planteamientos ideológicos, bajo los cuales se organizó en el plano de la crítica y de la teoría, de la práctica o de la pedagogía, puede ser clasificada con el término suficientemente ambiguo de "moderna" (connotación de "nuevo", "distinto", "reacción al pasado"), pero en el hecho, este período es un continuum de modernismo y revisionismo. Culminará con el "postmodernismo", avance a lo moderno, para volver al pasado. Así, aparecería una constante, el retro vanguardismo; el redescubrimiento del pasado de la arquitectura como solución o contestación al presente ya obsoleto. Y apareció después el "deconstructivismo" como la "nueva arquitectura", a fines de los años 80. 


\section{REVITA DE URBANISMO \\ http://revistaurbanismo.vchile.cl}

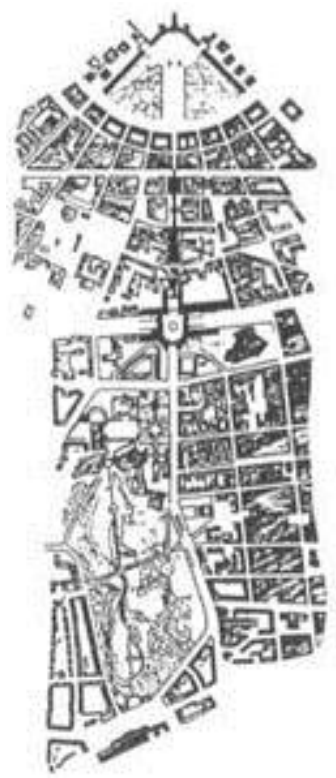

Fig. 5. Rediseño de la Vía Triumphalis, Karlsruhe, Rob Krier, 1979.

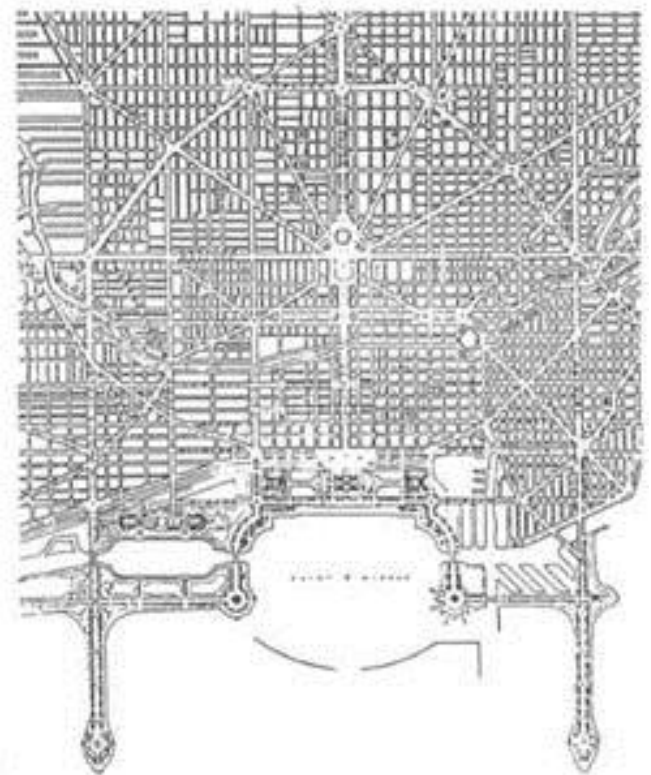

Fig. 6. Plano del sector central de Chicago, Daniel Brurham, 1909.

La idea de "modernismo" contiene implícitamente, la idea de "globalidad" y "radicalidad" (7), sea como método, estilo de vida o cosmovisión. Realmente el "urbanismo", o el "diseño urbano", son términos que intentan establecer fronteras o relaciones más amplias de una arquitectura que aparecería demasiado restringida en sus métodos y campos tradicionales. 
Otra connotación de la "arquitectura moderna" es su "racionalidad"; su expresión funcional y técnica objetiva, holística y científica, como la manifestación eficiente y concreta de la época industrial (8). Sin embargo, el método, la enseñanza y la crítica arquitectónica han sido ahora como nunca, plurales, ambiguos, cuestionables por su subjetividad, y el arquitecto nunca se ha presentado con tanta multiplicidad de enfoques. Muchos, como los de Soleri y OMA bordearon la magia, o - en la culta expresión Pop y vernácula de Venturi- están orientados a la búsqueda de la "complejidad y contradicción" como punto de partida. La fórmula del "menos es más" de Mies, va al "más no es menos" de Venturi, para reflejar que coexisten cada vez más elementos y posiciones, y que en la dialéctica arquitectónica en forma creciente, la discusión y las construcciones dejan cada vez menos perfilada una concepción básica de lo que es "más" o "menos", para los arquitectos y público en general.

La concepción de la arquitectura moderna y sus ideales aún permanecen como un sustrato de un verdadero "canon clásico". Las virtudes racionales de la ingeniería (lógica, función y geometría), y las características visuales del arte abstracto (planos blancos, formas simples y balance asimétrico) llegaron a ser un estilo, más allá de la ideología. Este estilo Moderno se puede yuxtaponer a los estilos clásicos anteriores, y así es posible sostener que la complejidad y contradicción de Venturi sería una nueva expresión del barroco o de la vuelta al vernáculo sofisticado de la costa Este de los EE.UU.

A partir de 1970, se ha producido un interesante avance en el plano de la teoría urbanística, un planteamiento de mayor integración disciplinaria y el cuestionamiento del funcionalismo de la ciudad CIAM. Las posiciones historicistas, el "sentido del lugar" y la "significación e identidad" del paisaje urbano como memoria colectiva, son resaltados. Aparece un gradual revisionismo y la incorporación de conceptos formales y tipológicos a la urbanística, especialmente en Europa. La Trienal de Milán de 1973 (participación de A. Rossi, Gregotti, Aymonino y R. Krier), enmarca el lanzamiento del "neo- racionalismo" o "post- modernismo", que se aboca a la reconstrucción de un pensamiento y praxis sobre la ciudad como hecho social y forma colectiva.

La urbanística tomaba posiciones demasiado diferentes: la preocupación sociológica basada en el empirismo de la Escuela de Chicago, y que se expresaba en una crítica social y económica, continuada por J. Jacobs y A. Reiss (9) ; también la posibilidad notacional de la imagen urbana, "la imaginabilidad" de Lynch o las experiencias del "paisaje urbano" inglés, el incrementalismo formal de Gordon Cullen, y finalmente, la ciencia ficción de los metabolistas japoneses, el inclusivismo "pop" de Las Vegas y el paisaje del Disney Wold americano, sostenido por Venturi. La crítica feroz de Jacobs sigue a una tradición que se había iniciado con Munford (10), sobre una ciudad mecanizada, inhumana, y corruptora de los ideales de una mejor sociedad. La metodología de Lynch o el "incrementalismo" de Cullen, suponían que en la imaginabilidad, secuencialidad y recorrido de los espacios urbanos puestos a escala, estaría la posibilidad de un nuevo diseño urbano democrático y participativo, de lo cual las Ciudades Nuevas inglesas eran un tedioso y poco inspirado laboratorio. 
Pragmatismo por un lado, vernacularismo y surrealismo por el otro, (Stanley Tigerman), entusiasmo por las cosas como son, se hacen y que finalmente se botan. Lo banal era transcendente por su propia fuerza vital. La arquitectura que se hacía en gran parte de los EE.UU. - a excepción de ciudades con gran refinamiento intelectual como Boston o Philadelphia y algunos condominios privados- se expresaba en los poderosos centros de Houston y Dallas, en grandes "shopping centers", Marinas en Florida, en los "malls" del medio Oeste, en la Plaza Italia, de Moore, pero sobre todo, en Disney World. Un mundo Pop de fantasía, consumista y nómade, Venturi, Moore y Phillip Johnson vieron la posibilidad práctica y teórica de reformular lo obvio del mercantilismo corporativo como "complejidad y contradicción", iy llegó a Latinoamérica como avalancha! "Glass in more".

Los japoneses, por su parte, manejaron sus problemas urbanos con una mezcla inexportable de alta tecnología, ciencia- ficción metabolista y megaformas, replanteando una ciudad de termitas para el mundo post- industrial, la que apareció, con variaciones en los conjuntos habitacionales sociales de México, Venezuela, Argentina, Francia, Alemania y U.R.S.S.(11). El vanguardismo entre el 60 y 70 era aceptar el presente con todas sus contradicciones especulativas y técnicas (Vernaculismo, pop, F.H.A. y H.L.M.), o avanzar al futuro con megaestructuras y ciudades paralelas (Tange, Friedman, Isosaki, Archigram).

Obviamente sucedió lo inesperado: la búsqueda del pasado y la resurrección de la ciudad clásica. El tipo, el estilo y la arquitectura como arte público, y como redescubrimiento, en el más alto nivel de "autonomía". Una nueva posición historicista, auto evidente, inclusiva y que dejaba contentos a los sofisticados planteamientos teóricos de la Escuela de Venecia, de Nueva York, igualmente que a las reproducciones más banales de los franceses, permitía volver a una arquitectura esquemática, icónicamente fácil como en los Krier y, una vez más, redescubrir un nuevo estilo que garantizara al arquitecto la idoneidad formal del producto y evitara las enojosas contradicciones y cavilaciones que demanda cualquier proceso serio de gestión humana. Con los trabajos de los Krier y el gradual transplante de nuevas formulaciones en varias escuelas de Arquitectura y revistas de EE.UU. y Europa Occidental, aparece en Venecia, Barcelona, Londres (Architectural Association), Nueva York (Institute for Urban Studies), incluso en Santiago (CEDLA), una alternativa nueva para el diseño de ciudades que se engloba entera en el término "neo- racionalista": la forma debe ser expresada "con lógica claridad y simplicidad"(12). 


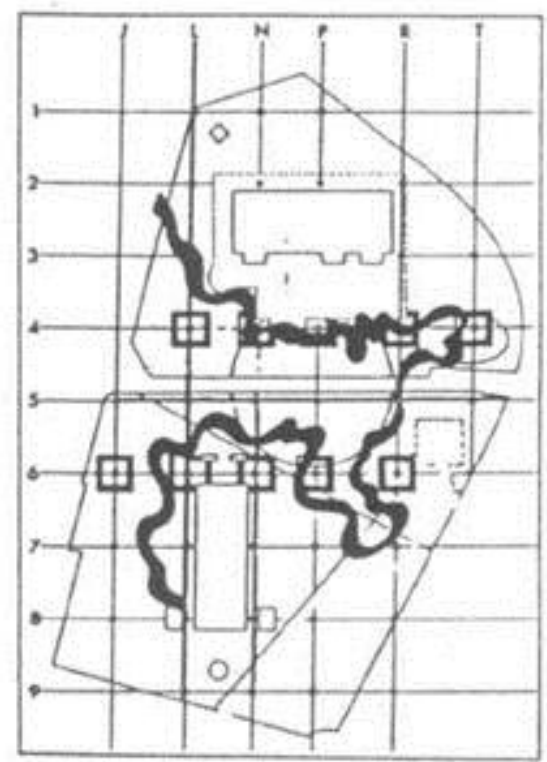

Fig. 7. Paseo cinemático, Bernard Tschumi.

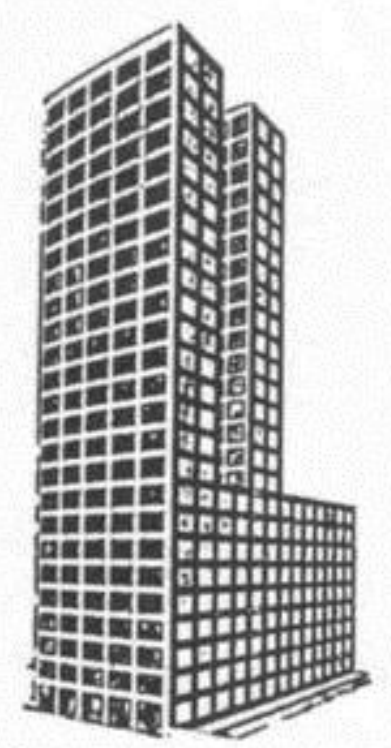

Fig. 8. Edificio de oficinas del "Chicago Tribune", Ludwig Hilberseimer, 1922.

Desde 1970, la teoría y discusión sobre la forma urbana y ciertos esquemas sobre su estructuración en unidades o elementos, los "barrios" (Rossi), o la "fachada", el "portal", la "calle" y otros elementos tipológicos (R. Krier), son básicos. La solución a la ciudad sólo se daría en una expliCitación: formal "arquitectónica" y "autónoma", pero, 
sobre todo, "histórico" y "agregrativa". La semiología se constituye en base de la nueva arquitectura, reemplazando al funcionalismo anterior.

El grupo de OMA (The Office for Metropolitan Architecture; Arqtos: Koolhass, Vriesendorp y Zenghelis), avanzó hacia un diseño urbano inscrito en el expresionismo surrealista (13). Detrás de sus propuestas urbanas para "El Parque de los 4 Elementos", la "Ciudad del Globo Cautivo", o el "Hotel Welfare Palace", hay preocupaciones sobre la ciudad, el símbolo y el uso de formas cargadas de referencias, pero que llevan al más puro formalismo escenográfico. ¿No es esta especie de nueva utopía, la reencarnación de los artificios mecánicos del Archigram, pero con un sabor a arquitectura surrealista o constructivista de 1920? La construcción se reemplaza por el dibujo. No hay diseño urbano, ni una arquitectura coherente en estos proyectos de pretenciosa monumentalidad. En cualquiera posición que se estuviera con respecto al Urbanismo, es necesario preguntarse sobre qué modelo o teoría de ciudad se construye esta posición. Rowe señaló que no se puede plantear una teoría de la ciudad, si esta no se sostiene en una teoría de la Arquitectura y en una teoría de la sociedad en conjunto (14). Siendo la ciudad un hecho arquitectónico y social, aparecía notorio que el idealismo utopista, el activismo o el funcionalismo moderno carecían de una teoría social suficiente. Y que, entre teoría de la planificación y teoría de la arquitectura, no aparecían aún claras las relaciones, y que por lo menos, era posible volver a revisar la propia teoría de la arquitectura.

Dos líneas de argumentación se van contraponiendo: los ideales composicionales, el utopismo social, el activismo y el formalismo de la ciudad funcional, y un inclusivismo historicista mezclado con vernacularismo. El proyecto de la planificación y zonificación del CIAM, pasa al metabolismo y a los sistemas y mallas complejas, para concluir en el post- moderno, en un formalismo alusivo, en el rescate de las tipologías de la ciudad histórica. "La forma sigue a la función", del CIAM, requería simplificar o ideologizar las complejas funciones de la vida urbana. ¿Por qué no sustituir el argumento y volver a que la "función sigue a la forma"? Así, y desde la arquitectura, cualquier edificio sería relevante, si se manifestara "con referencia a". De aquí el historicismo, la semiótica arquitectónica, y la metáfora, que aparecieron, si no como causa, como su efecto. La ciudad "histórica" pareció más humana que la ciudad "moderna" y esta fue la importancia de Aldo Rossi.

En ciertas revistas, centros de estudio y arquitectos del "establishment" estaría la salida que orientó, desde 1976, a la "nueva arquitectura". Por un lado, vernacularismo y arquitectura local, por otro, historicismo y reconstrucción de la arquitectura clásica, $y$, en todas partes del mundo, un surgimiento extraordinario de nuevos arquitectos de a Cuarta Generación que volvieron a poner a la arquitectura en tensión crítica entre lo que se piensa y lo que se construye. La ciudad fue aceptada como escenario ambiguo e incremental de una batalla incesante entre diseño, construcción y gestión, entre gestos estéticos extraordinarios y técnicas transfiguradas en materiales y detalles.

Nuevos procesos de renovación urbana realizados en Boston, San Francisco, Philadelphia, Milán, Bruselas, París, Dusseldorf, Jerusalén o Córdoba, lo han demostrado. Una concepción científica y progresista, junto a una arquitectura más 
humanista e históricamente significativa, han servido para una mayor concentración de lo que Rowe llama las "fantasías de la Arquitectura Moderna" que aún permanecen: la nueva arquitectura era determinable racionalmente, predestinada históricamente, una respuesta al espíritu de la época, y socialmente terapéutica. Joven, renovable en sí misma, y por lo tanto "incambiable en el tiempo"(15).

Las investigaciones de Rossi, Aymonino y del Grupo "Architettura", trataron de salvar el abismo conceptual y teórico que existía hacia 1970, entre el "planning" y la arquitectura urbana (16). Cuando los edificios llegan a ser monumentos, y la ciudad es memoria colectiva que debe ser rescatada, o cuando se recalcan los términos de "tipología edificatoria" o " morfología urbana", se está hablando de algo, cuantitativa y cualitativamente diferente a la construcción de un edificio. De algún modo curioso la contradicción entre ciencia positiva -visión constructivista e ingenieril- y humanismo visión antropológica- pareciera reducirse.

"Una arquitectura como historia", una arquitectura como un "elemento permanente en la ciudad", y "una arquitectura como construcción", llegan a ser tres postulados básicos en la Escuela de Venecia. Merecen resaltarse, pues tienen especial aplicación en la ciudad del Tercer Mundo de la arquitectura latinoamericana por su ausencia.

Al acentuarse la -autonomía- de la arquitectura, se va redefiniendo la intervención en la ciudad. Nuevamente la morfología total debe primar. Una contextualización sutil de un ente total, que se constituye en el tiempo es la base de "una arquitectura de la ciudad"(17). La mera intervención desde el objeto aislado o del plan geométrico y racional del CIAM, ha dejado lo que llama Rowe, a una ciudad "no construida".

Ahora el protagonismo del edificio y el rescate de la autonomía disciplinaria de la arquitectura, no significarán lo mismo. La idea del "monumento" y "espacio público" en Rossi son básicas para generar espacios articulados, de carácter especialmente significativos, para resaltar una unidad de barrios y entes opuestos (18). La ciudad puede y debe acomodar propuestas de diferentes épocas para establecer la necesaria relación entre ellas. Esta idea está explícita, como "ejercicio gimnástico para la imaginación", en la exposición de "Roma Interrotta" en 1979.

En un plano antropológico y teórico más profundo, la ciudad como "teatro de la historia" y como "teatro de la profecía" de Rowe, se asimila con la "ciudad análoga" de Rossi. La superposición de texturas, el "bricolage" que destaca Rowe, un trabajo de "sutura", de "remiendo" en una ciudad "destrozada" sería una política posible. Solución imperfecta que aparece como estrategia y que la planificación urbana debería aceptar e incorporar.

La tesis que surge, cada vez con mayor convergencia, es la de rescatar -por un trabajo morfológico afinado- una estructura posiblemente ambigua, integrándose aún con posibles sectores contradictorios, resaltando las formas, permitiendo una humanización de la ciudad por una escala asociativa menor de la intervención y por las referencias ambientales. Permite una amalgama aparentemente incoordinada de pedazos, una multiplicidad de estímulos y complejas combinaciones (19). De la historia de Roma a 
http://revistaurbanismo.uchile.cl

Londres, como ejemplos que rescata y realiza, Rowe cree que este enfoque de una Ciudad Collage, como conjunto variado de intervenciones agregativas, se puede aplicar sobre Los Ángeles, Houston, o hasta en Manhattan, rescatando en cada una de las ciudades los sectores, barrios y estructuras fundamentales que la morfología analítica manifiesta.

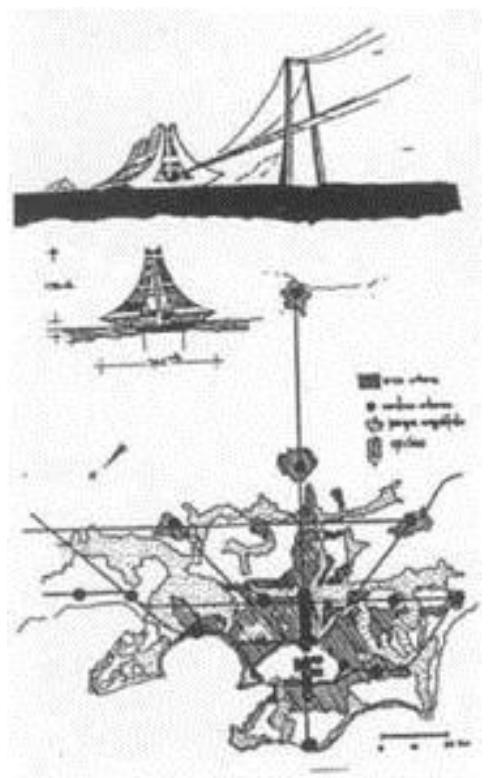

Fig. 9. Plan de Tokio - Megapolis Tokaido 2000, Kenzo Tange, 1960.

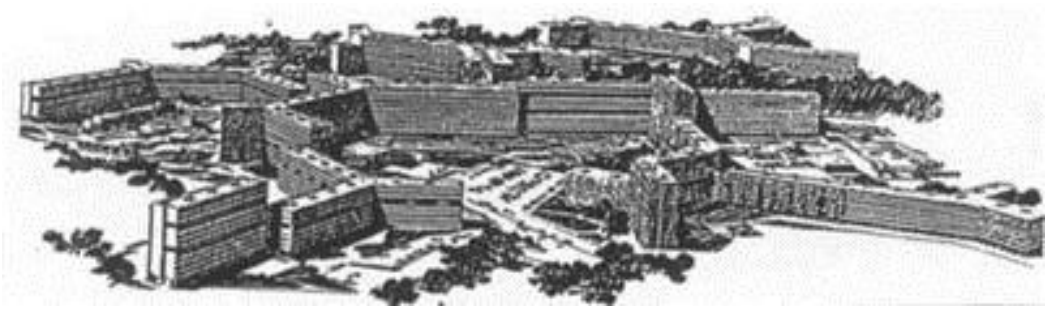

Fig.10. Ciudad para 100.000 habitantes, J.J. Candilis - Josic- Woods, 1961.

\section{Los Paradigmas de la Forma Colectiva}

Concluyo ordenando los temas anteriores en ciertos paradigmas complementarios, que intentan una clasificación y soslayan la simple confrontación dialéctica entre Modernidad y el Post- Modernismo por no ser suficiente (20) y hoy más que nunca, irrelevante (21). 
Englobando más allá de las tendencias, que se prestan para juicios fáciles, es posible destacar los "paradigmas" que explicitan una determinada teoría de la forma y el espacio, una metodología de construir y concluyen con un determinado arquetipo. No es de extrañar que incluyan, como en las "pulsaciones" de Jencks, los revisionismos de una posición ya establecida, o avances y modelos inéditos con categoría y elementos nuevos que permitirán el reestablecimiento del espacio y la forma urbana desde un modelo original. Las Escuelas, y los paradigmas que las caracterizan, toman una cierta ordenación cronológica. Las condiciones técnicas y sociales en los últimos cien años tienen una progresión, una continuidad dentro de contrastes y revueltas. El espacio y la forma, la tecnología y las construcciones en lo material, se reflejan en algunas cuestiones que hoy son básicas:

- El sistema de agregación o crecimiento de la forma. Su cambio u obsolescencia natural o planificada (METABOLISMO).

- La delimitación, integración o contraste con el medio natural. Su grado de simbiosis o autonomía (ENTROPIA).

- El tamaño y componentes de la forma colectiva y su organización jerárquica (ESCALA).

- Su grado de autonomía tecnológica; adaptabilidad y control ambiental, construcción e industrialización (AUTOPOIESIS).

- Su carácter funcional, apropiación cultural y antropológica (PROXEMICA, ESPACIO EXISTENCIAL).

- Finalmente, su carácter, identidad y significado (SEMIOTICA).

Estos seis aspectos permiten caracterizar las tendencias en base de cuatro paradigmas. Esto, suponiendo que como arquitectura, reflejan un conjunto consistente de experiencias y valores, cuya materialización formal y expresión significante los hace resaltar de la caótica y banal realidad con que se construyen tantas de las ciudades de nuestro tiempo; lo que mi maestro Fumihiko Maki (Premio Prietzke 1993) califica como el "incrementalismo disconexo", la ciudad sin modelo, alejada de una idea matriz de la cultura cívica. Ciudad visualizada y valorada como futura realidad, como proyecto y utopía de la sociedad urbana que puede y debe ser construida. De allí lo importante de polarizar y discutir estos paradigmas. 


\section{REVISTA DE URBANISMO

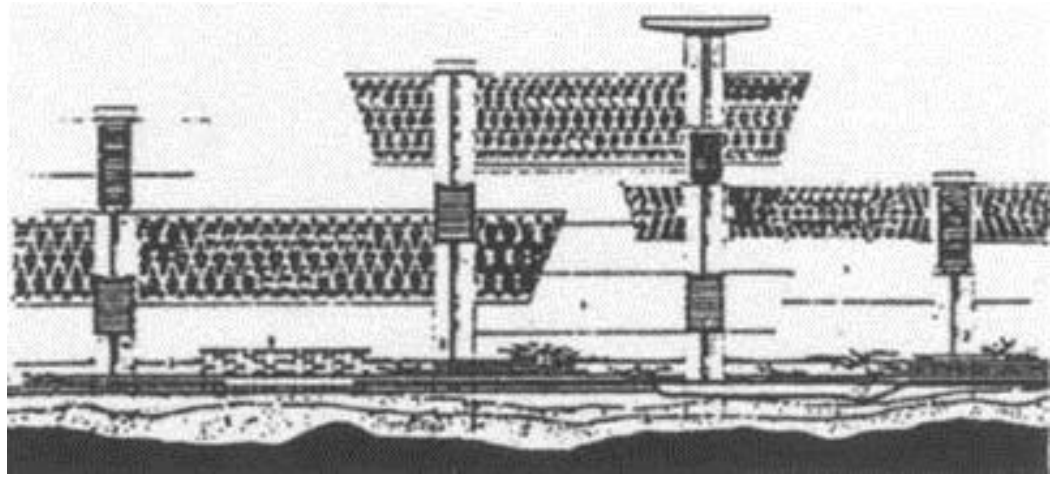

Fig. 11. Plan de Tokio, eje comunal, Kenzo Tange, 1960.

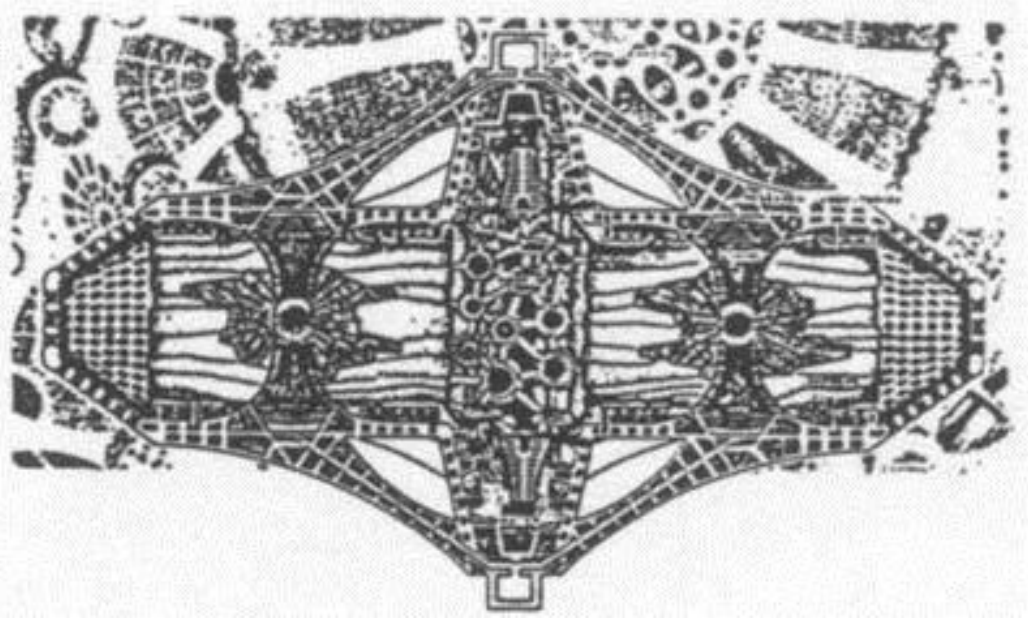

Fig. 12. Planta de ciudad ideal de fuente económica agraria, Paolo Soleri. 


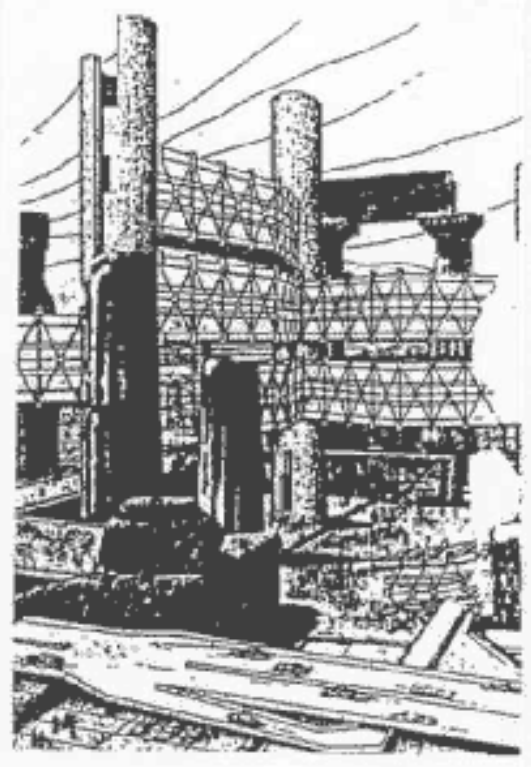

Fig. 13. Proyecto de ciudad espacial, Arata Isozaki, 1960.

\section{El Formalismo Canónico}

Es el paradigma "clásico" de la arquitectura. Resalta la forma geométrica externalizada en reglas de composición, e integra el espacio como contenido y la construcción como un continente no explícito necesariamente. Utiliza normas racionalizadas de carácter sintáctico y significante, al estilo, los órdenes y los tipos caracterizados como referencias. La preponderancia de la forma sobre la función y el significado, está determinada y codificada por la norma estética. La forma construida es un objeto y el contraste entre espacios positivos y negativos es característico en la composición urbana. Es un paradigma racionalizado $y$, por lo tanto, de fuerte permanencia histórica. Son ejemplos: Los Falansterios y ciudades desde la tradición Renacentista y Barroca (Scamozzi, Filarette, Wren), el Plan de París, de Hausmann, y Washington D.C. (L'Enfant). Cobra gran importancia a comienzos de siglo, en la obra de Bumham la "City Beautiful" (Chicago, Manila y San Francisco, el "Stadtebau" de Sitte y Otto Wagner. Aparece con algunas variantes contemporáneas en Brasilia de Costa y Niemayer. El formalismo reaparece con la "autonomía" de la arquitectura y el retrovanguardismo, desde 1975 en adelante (los Krier, Rossi, Graves, Bofill, entre otros).

\section{El Constructivismo Funcionalista}

Resalta la función y la materialización constructiva de la ciudad como una máquina. Espacialidad y significado serán las consecuencias de una concepción racional y constructiva. La materialidad y la tecnología serán explícitas, brutales y externalizadas, tanto las propiedades físicas del material, del color, la textura, la resistencia o las o las instalaciones mecánicas. Implica un diseño urbano instrumentalizado, un alto grado de 
profesionalidad y tecnología (high- tech) aplicada a una ciudad eficiente y funcionalmente zonificada y construida. Son importantes la vialidad y el transporte. Aparece en prototipos de gran interés en las ciudades de Leonardo, en las estructuras de Piranesi y en la "Nuova Cittá" de Sant' Elia, así como en las propuestas constructivistas de los años 30 de Tatlin, Lissitsky, Meyer, Hilbersheimer y Korn. Son ejemplos la Ciudad Funcional del CIAM, Plug-in- City, el Archigram, los "modelos" de Martin y March, así como la estructura de "soportes" de Habraken. Algunos ejemplos son inconstructibles y este paradigma tuvo su etapa de modelo prospectivo en los años 60 (las estructuras para París de Y. Friedman, las estructuras "A" de Tange, etc.), o la accidentada construcción y gradual ajuste y humanización de Brasilia y Chandigarh.

Una expresión muy ilustrada está en el propuesta de Wampler para Boston del Bicentenario de 1976. Es así un paradigma de megaforma y formas composicionales, de una sintaxis explícita y de una rigurosa lógica de construcción del espacio y forma urbanos. Las propiedades significantes son dadas por el formalismo que es continuista, de "modernidad" y en oposición al decorativismo y las propiedades eclécticas o subjetivas de una arquitectura más subjetivizada. Aparece con el "Deconstructivismo", la obra de B. Tschumi, la remodelación de Yokohama y la obra de Frank Gehry.

\section{El metabolismo organicista y sistémico}

Se resaltan las partes o componentes integradas en un total urbano extendible como sistema. Las jerarquías y complejidad de organización de la ciudad -como ente vivo- la constituyen en una contrapartida a los dos tipos anteriores. Se resalta una gran simbiosis con el medio, incluso con un alto grado de tecnología. Paradigma implícito en la Teoría Ekística y en los "sistemas" de Alexander; y explícito en las formas orgánicas de Soleri (Arcosanti) y en la Casa Dymaxion de Fuller; en las "estructuras inflables", en las propuestas del Team 10 (Smithson, Candilis, Josic, Bakema), sobre todo, en el Metabolismo de los japoneses (Tange, Kurokawa, Maki) y en la obra de Safdie. Son referencias importantes las obras del Arqto. Erskine, Kroll y Hundertwasser, destacando aspectos vernaculares y espontáneos. Es un paradigma de gran interés prospectivo. Bacon aborda un enfoque metabolista para Philadelphia, pero su paradigma es convencionalmente constructivo. Maki enuncia este paradigma en "Sistemas de Movimiento para la Ciudad". La teoría del "fragmento" y adaptabilidad de Rowe, refuerza un paradigma agregativo más que sintético. Se ha formalizado en megaformas de gran interés y en formas grupales y combinables, especialmente por la adaptabilidad y capacidad agregativa y de crecimiento del modelo. Requiere de gran nivel de tecnología y planificación.

\section{El expresionismo onírico: metáforas y surrealismo}

La ciudad vivencial y síquica, en que los niveles existenciales y significativos del paradigma son subterráneos o superpuestos en relación con la realidad construida. Es un paradigma vigente desde el utopismo a la metáfora literaria o religiosa y social (la Torre de Babel, la "Utopia" de Moro, la "Ciudad del Sol" de Campanella, o la "Ciudad Análoga "de Rossi), y llega permanentemente desde la esfera de lo no racional, o de las estructuras sociales o políticas más profundas y significativas. El Barroco resucita 
este paradigma en las "Residentzstatten" y en las construcciones teatrales y escenarios de las fiestas palaciegas y urbanas de las Cortes de la Ilustración. Es un paradigma literario y escenográfico. Se presenta en ciudades "metafísicas" de tipo religioso de la antigüedad (Acrópolis, Roma, ciudades Mayas o Incas). Las ciudades de Krier, las propuestas de O.M.A. y de "Roma Interrota" citadas, son ejemplos contemporáneos de este enfoque expresionista y onírico. Es un paradigma de los tiempos de crisis, en que desde Hiroshima a Calcuta, o de México a una "favela", se desintegra la concepción racional y formal de la ciudad; trae una contrapartida radicalmente diferente y esencialmente subjetiva y poética. Se intenta, como utopía, otra alternativa a la ciudad de la "naranja mecánica", del hombre socializado en la anomía de la metrópolis. Así ya sucedió contrastada entre Roma en el siglo III y en el paradigma de la Villa Adriana. Se presentó en el incendio de Watts, en Chicago, en Los Ángeles y Nueva York en los años 60, originando la "contra- cultura" y la "ciudad no- ciudad" de la autopista, de los "Siedlungen" alemanes incendiados por sus futuros ocupantes en 1967 y expresada, sobre todo, por el cine y las artes visuales. Aparece como escuela y construcción en América, y en la Ciudad Abierta de Ritoque, Valparaíso. La "ciudad de los sueños" es la ciudad de los tránsfugas, formas agregativas y metáforas, formas alusivas muchas veces extraordinarias pero separadas y enajenantes. Un paradigma que se repite en Babilonia y Gizeh, en Cluny y Avignon, en San Petesburgo y Versalles, en Nancy, Postdam, Berlín IBA y Kyota. Utopías que no serán realidad, pero que revelan el problema de una sociedad que, como dice Rowe, no reconoce su falta de propuesta.
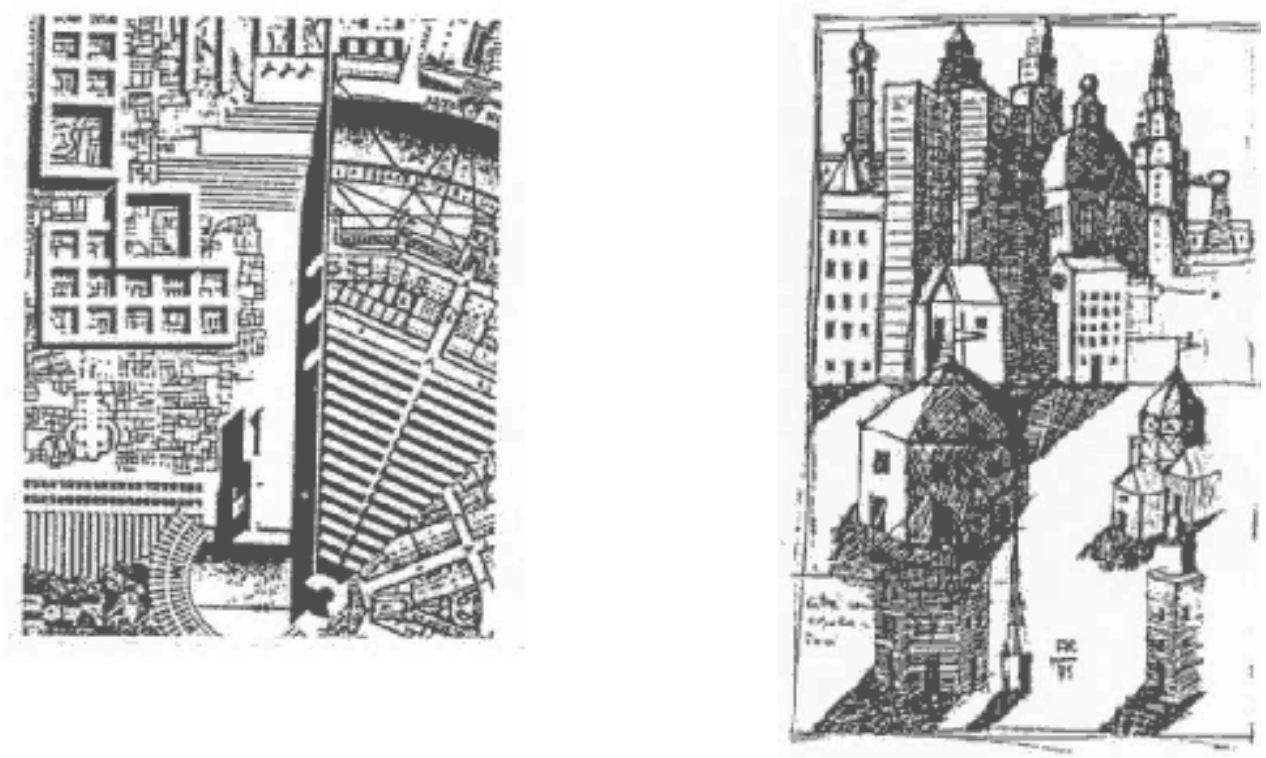

Figs. 14 y 15. Ciudad Análoga, Aldo Rossi. 


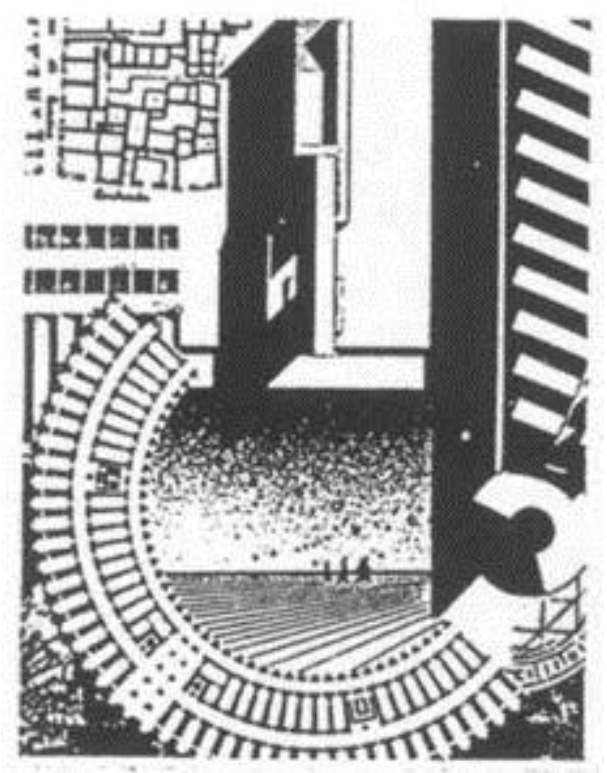

Fig. 16. Proyecto de Roma Interrotta, Graves, Krier, 1979.

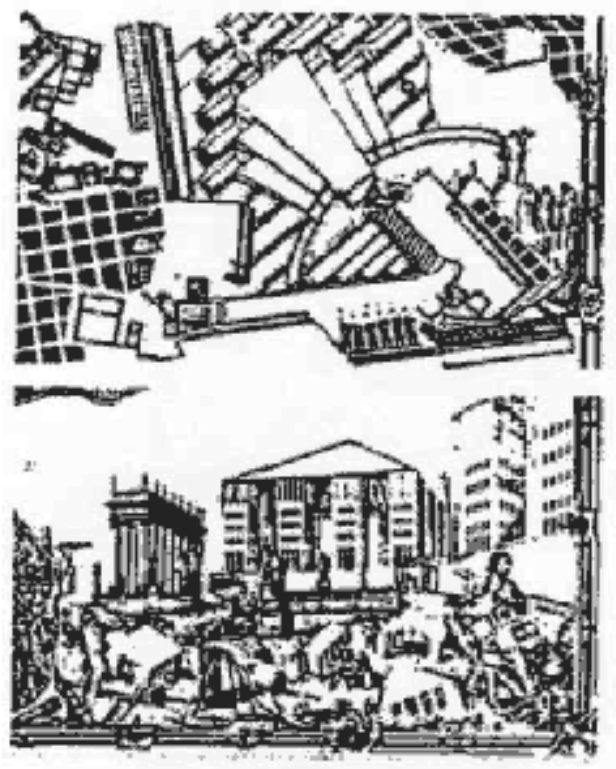

Fig. 17. Imagen de una ciudad. El espacio público y el monumento, Aldo Rossi. 


\section{Conclusión: historia y naturaleza, ciencia y participación}

Una arquitectura urbana en el futuro podrá surgir sin un paradigma de forma. No será necesariamente ni más moderna ni más antigua, sino distinta. Las clasificaciones presentadas se esbozan solamente para revelar la coyuntura del presente ante la paradoja del pasado que vuelve a ser propuesta. El constante volver a intentar resolver el problema de una sociedad por una "forma de construir" lo que ni por analogía manejamos todavía los alcaldes, los especuladores ni los arquitectos. Tampoco los ciudadanos mal informados y poco escuchados...

Con respecto a la ciudad como proyecto contemporáneo - expone Rowe- "hemos creído los arquitectos en una arquitectura de fantasía de ciencia y libertad". Podemos agregar; sólo en el hemisferio Norte; de mera representación y de gran miseria en el hemisferio Sur. La concepción científica y progresista, así como la fantasía histórica y significativa, han hecho expandirse las utopías por el planeta en forma creciente, y el cine y los medios de comunicación las van convirtiendo en una supra- realidad que se desborda desde las revistas de Arquitectura hasta las Escuelas, y de allí a una profesión marginalizada. Se evita así, muchas veces, la visión real de las ciudades en que vivimos, o los problemas humanos y de geografía que precariamente controlamos y rara vez intentamos planificar.

El discurso o la retórica también se expanden y parodiando las condiciones que señalaba Rowe:

- la "nueva arquitectura es determinada racionalmente", agrego, que la nueva arquitectura trasciende, muchas veces, a toda realidad técnica para ser sólo dibujo para exposiciones.

- la nueva arquitectura es "respuesta al espíritu de la época", pero vivimos en un mundo de historias diferentes, paralelas, 0 superpuestas. - La nueva arquitectura "debe ser socialmente terapéutica", pero hoy la realizan la especulación y el lucro, o la abandonan los arquitectos -por imposible- en los barrios marginales de América

Latina.

- La nueva arquitectura "será joven y renovable, incambiante con el tiempo", pero se revela pocas veces como algo bien construido y que permanece. El edificio moderno se ve viejo a los diez años.

Quizás, podemos suponer la salida en el ideal ético; una nueva arquitectura de la ciudad que implique "el fin de todo engaño, decepción, simulación, vanidad, subterfugio e imposición"(22). Quizás en los fragmentos de ciudad, pedazos del mundo que los hombres logramos rescatar, estén los paradigmas, pero de una ciudad que no sabemos aún quién, no cómo se edificará. Y de la fatalidad de la ignorancia y del control de la técnica ajena, o la tiranía de las minorías dominantes. ¿Cuál es lo más disfrazado del submundo urbanizado de la ciudad de los pobres que pueblan dos tercios del planeta? 


\section{REVISTA DE URBANISMO

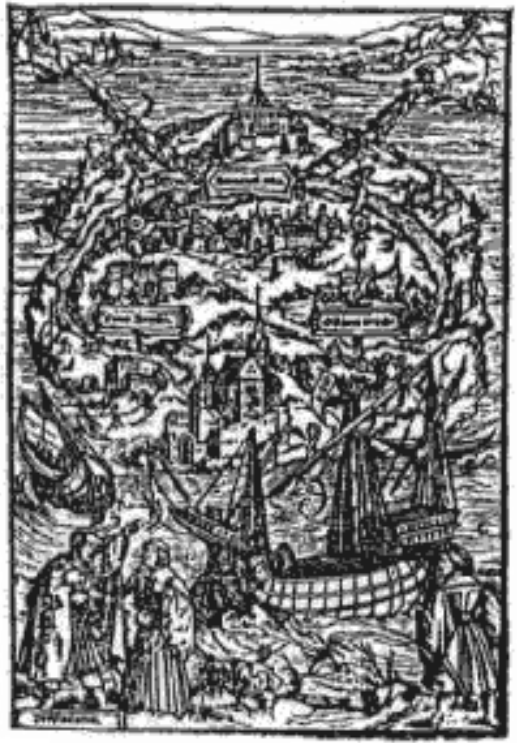

Fig. 18. "Utopía", Tomás Moro, (portada de publicación), 1516.

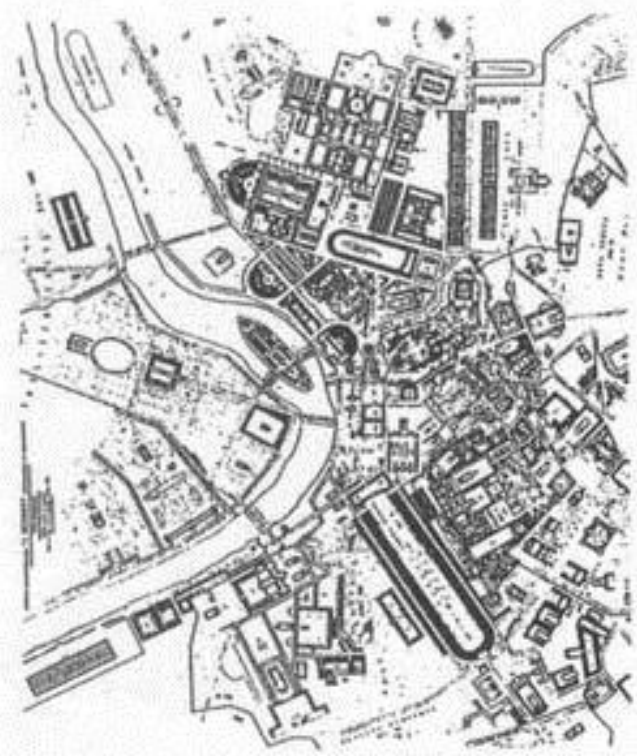

Fig. 19. La Roma Imperial, según Canina (1834).

Hoy se puede ser propositivo y optimista, porque aún es posible y necesario. Desde ya, las posibilidades de aplicación de la ciencia y la organización participativa de la sociedad serán el único límite con el cual un diseño urbano relevante, más sabio y humano, puede surgir. Podemos ver lo mucho y completo que se ha asumido sobre la 
ciudad como un recorrido de experiencias y temáticas dispersas pero interdependientes. Lo mucho que queda por reconstruir de la idea y práctica de la ciudad como conocimiento y verdad. No aparecerá una propuesta de método ni de teoría suficiente, ni menos un modelo de ciudad, pero sí las señales, las orientaciones y una guía, para una consciente y responsable acotación de preguntas importantes que ya antes se han hecho; para comenzar a buscar en las Escuelas y en la profesión, las respuestas que nuestro mundo y tiempo requieren. Sobre el urbanismo y las posibilidades efectivas de una arquitectura que incluya la naturaleza y la ciencia, la sociedad y la cultura. Ciudad como utopía, el "teatro de la profecía" y ciudad en la historia, el "teatro de la memoria". Quizás al plantear estos temas ya hemos comenzado a caminar una nueva etapa (23).

\section{Referencias}

(1) MUNIZAGA, Gustavo. Diseño Urbano: Teoría y Método, Facultad de Arquitectura y Bellas Artes, Escuela de Arquitectura, P.U.C., Ed. Universidad Católica de Chile, 1992, 336 págs. Ilustradas. Vid. Capítulo.

(2) Ver: Adna E. WEBER, The Growth of Cities in the XIX Century, Cornell, 1895. El término "Urbanology" es utilizado por Daniel P. MOINHAN, como la ciencia global de las ciudades, en Revista Time, mayo, 1968.

(3) Entre ellas: C. Abrams, del MIT; E. Bacon, D. Gral. de Planificación de Philadelphia; P. Bigador, D. Gral. de Planificación del Ministerio de la Vivienda de España; C.S. Chandrasekhara, S. Gral. de la Organización Regional de Planificación y Vivienda para el Asia Oriental de la ONU; W. Christaller de Alemania, creador de la Ciencia Regional; J. Crane, de los E.E.U.U.; Lord L. Davis, Decano de Arquitectura, U. de Londres; B. Fuller; S. Gideon; Lady B. Ward Jackson; Sir R. Mathews, Presidente del Instituto de Arquitectos Británicos; Margaret Mead (E.E.U.U., Antropóloga).

(4) MAKI, F., Investigations in Collective Form. BACON, E., The Design of Cities, y SPREIREGEN, P., Urban Design; The Arquitecture of Towns and Cities.

(5) JENCKS, Charles, Arquitecture 2000, pág. 35, 1971

(6) En 1973, PAWLEY y TURNER visitan Chile, y en la F.A.U. de la U. de Chile se desarrolló un taller sobre "Vivienda de Desechos-Garbage Housing".

(7) MUNIZAGA, Gustavo. El Diseño Urbano como Teoría y Método, E.A.-P.U.C., Santiago 1990.

(8) JENCKS, Charles, Op. Cit., pág. 36.

(9) JACOBS, Jane, Life and Death of American Cities, y REISS, Albert, La Metrópoli en la Vida Moderna, B. Aires, 1961.

(10) MUNFORD, Lewis. La Cultura de la Ciudades, 1957.

(11) Referencia a los proyectos "oficiales" de estos países presentados al Congreso U.I.A. -B.Aires, 1969.

(12) G. CEDLA, Folleto de conf. Arquitectura Neo-Racionalista, Stgo, 1976.

(13) Ver Architectural Design, Vol. 47, № 5, 1977, págs. 319 a 356.

(14) ROWE, Collin, Collage City, M.I.T., Press, 1978, pág. 6.

(15) ROWE, Collin, op. cit., pág. 6. (16) SEMERANI, Luciano. "The School of Venice", en: Arquitectural Design, 555/6-1985 555/6-1985, pág.
10.

(17) ROSSI, Aldo. La Arquitectura de la Ciudad. Barcelona, 1971.

(18) ROSSI, Aldo. Op. Cit.

(19) ROWE, Collin. Op. Cit, págs. 90 y 110 a 112.

(20) MALDONADO, Tomás. II Futuro della Modernitá. Feltrinelli, 1987.

(21) De la Editorial Gustavo Gili, la publicación de la obra del arquitectura boliviano-chileno-español, Melvin VILLAROEL. Aquí veremos un nuevo ejemplo de cómo aparecen las raíces esenciales de una arquitectura apropiada y relevante, sin "ismos" ni trabajosos elucubraciones.

(22) ROWE, Collin, op. cit., pág. 3.

(23) Al desplome del mundo comunista ¿no seguirá el de la arquitectura como utopía del siglo XX? 